\title{
Determination of Ethanol in Gel Hand Sanitizers Using Mid and Near Infrared Spectroscopy
}

\author{
Fernando S. Fonseca Jr., ${ }^{a, b}$ Livia R. e Brito, ${ }^{\circledR *, b}$ Maria Fernanda Pimentel ${ }^{c}$ and \\ Leila B. Leal ${ }^{d}$
}

${ }^{a}$ Departamento de Química Fundamental, Universidade Federal de Pernambuco, 50740-560 Recife-PE, Brazil

${ }^{b}$ Instituto de Criminalística Professor Armando Samico, Polícia Científica, 52031-080 Recife-PE, Brazil

'Laboratório de Combustíveis, LITPEG, Departamento de Engenharia Química, Universidade Federal de Pernambuco, 50740-550 Recife-PE, Brazil

${ }^{d}$ Farmácia Escola Carlos Drummond de Andrade, Departamento de Ciências Farmacêuticas, Universidade Federal de Pernambuco, 52171-011 Recife-PE, Brazil

\begin{abstract}
Alcohol-based gel hand sanitizers became very popular during the COVID-19 (coronavirus disease 2019) pandemic. In Brazil, several irregular factories emerged requiring an efficient control by the police and regulatory agencies to guarantee product quality. This problem required a method to determine ethanol content, which led to the development of two methods employing mid and near infrared spectroscopy associated with chemometrics. Partial least squares (PLS) models were built and presented satisfactory results with mean absolute percentage error of prediction and root mean square error of prediction (RMSEP) of 1.12 and $0.76 \%(\mathrm{~m} / \mathrm{m})$, respectively, for mid-infrared (MIR) and 1.83 and $1.18 \%(\mathrm{~m} / \mathrm{m})$ for near-infrared (NIR). The analysis of commercial and seized samples of hand sanitizers showed that only 7 out of 34 samples had an ethanol content of $70 \%$ $(\mathrm{m} / \mathrm{m})$ or higher. This result reinforces the need for constant vigilance by authorities to ensure that the products have the required specifications.
\end{abstract}

Keywords: ethanol, hand sanitizers, infrared, PLS

\section{Introduction}

Due to the COVID-19 (coronavirus disease 2019) pandemic, the World Health Organization (WHO) has advised the public to clean their hands frequently to avoid contamination, causing alcohol-based gel hand sanitizers to become very popular. This has provoked a shortage of these products on the market. In order to counteract this, regulatory agencies worldwide such as the U.S. Food and Drug Administration (FDA) and the Brazilian Health Regulatory Agency (ANVISA) have issued guidelines for temporary preparation of these sanitizers by specific companies and pharmacies during this public health emergency in order to increase supply. ${ }^{1,2}$

In Brazil, ANVISA has also authorized the use of different feedstock than the ones recommended in the

*e-mail: 1.brito@ic.pe.gov.br
Brazilian Pharmacopoeia National Form. According to the Form, alcohol-based gel hand sanitizers should contain water, ethanol, carbomer 980 and triethanolamine. ${ }^{3}$ Carbomer 980 is the component responsible for the gel consistency of a hand sanitizer and can be substituted by other carbomers or cellulose derived components, such as hydroxypropyl methylcellulose (HPMC) and hydroxyethyl cellulose (HEC). Triethanolamine is a neutralizing agent used to adjust $\mathrm{pH}$ value to obtain gel consistency when using carbormers. It can be substituted by other compounds such as aminomethyl propanol (AMP) or other bases. Additional components such as glycerol may be added for skin care. Also, ANVISA requires the ethanol content to be at least $70 \%(\mathrm{~m} / \mathrm{m})$ and that the product must have proven antibacterial activity. ${ }^{4}$

Although necessary, this temporary dismissal of product registration has caused irregular producers to emerge, disregarding proper manufacturing practices 
and often producing hand sanitizers that do not meet the specifications required for destruction of the virus, which gives the users a false sense of protection. Therefore, constant vigilance by the authorities is required in order to avoid the commercialization of subpar alcohol-based hand sanitizers.

Law enforcement agencies, who are responsible for the apprehension of irregular products, require a reliable and practical method to determine the ethanol content in gel hand sanitizers in order to evaluate if the amount of ethanol matches the value indicated on the product label. Some methods based on gas chromatography (GC), specific gravity using alcoholmeter, hydrometer or pycnometer and spectrophotometry have already been proposed for the analysis of ethanol solutions. ${ }^{2}$ The problem with these methods is that the gel's viscosity hinders the usage of alcoholmeters and the other methods require specific equipment or destructive and time-consuming sample treatments. Mid-infrared (MIR) and near-infrared (NIR) spectroscopies associated with chemometrics are already being used to determine alcohol content in different kinds of samples such as beverages, fuels and fermentation broths. ${ }^{5-10}$

In this work, two methods were developed, both employing infrared spectroscopy, due to the fast and nondestructive nature of this technique and the small volume of sample required. One is based on attenuated total reflectance Fourier transform infrared spectroscopy (ATRFTIR) and the other based on a handheld NIR spectrometer (MicroNIR). Several law enforcement laboratories already have FTIR spectrometers or could purchase a portable nearinfrared device to be used for on-site measurements. These methods could also be used by the industry for quality control purposes.

\section{Experimental}

\section{Samples}

As the major components of alcohol-based hand sanitizers are ethanol and water, 13 samples of aqueous solutions of ethanol with concentrations ranging from 30 to $90 \%(\mathrm{~m} / \mathrm{m})$ were prepared with $99.8 \%$ ethanol (QEEL, São Paulo, Brazil) as well as 11 samples of gel hand sanitizers with ethanol concentrations ranging from 30 to $80 \%(\mathrm{~m} / \mathrm{m})$. Out of these 11 samples, 9 were prepared at the school pharmacy of the Federal University of Pernambuco (FECDA/UFPE). These contained anhydrous ethanol (donated by Pernambuco's ethanol plants), purified water, $0.5 \%$ of carbomer 940 (Dinâmica, Indaiatuba, Brazil) and AMP (Fagron, São Paulo, Brazil) in a sufficient amount to obtain a pH between 6 and 7, according to the instructions described in the Brazilian Pharmacopoeia National Form. ${ }^{3}$ As ANVISA ${ }^{1}$ has also authorized the use of different feedstock than the ones already described in the Brazilian Pharmacopoeia National Form, two samples were prepared by the Pharmaceutical Laboratory of Pernambuco (LAFEPE) using anhydrous ethanol (Transálcool, Olinda, Brazil), purified water, HPMC (Denver Especialidades Químicas, Cotia, Brazil), and glycerol (Codossal Química, Recife, Brazil). Two of these 11 gel samples were used to compose the calibration set and the remaining were employed in the external validation set, as described in the Results and Discussion section.

In addition, 27 samples of commercial gel hand sanitizers were acquired in Recife plus 7 samples taken from seizures by the Pernambuco State Civil Police.

\section{Data acquisition}

A FTIR spectrometer (Spectrum Two, PerkinElmer) was employed for the acquisition of MIR spectral data. The spectra were acquired in the $650-4000 \mathrm{~cm}^{-1}$ range by averaging 4 scans with absorbance measurements every $1 \mathrm{~cm}^{-1}$ and spectral resolution of $4 \mathrm{~cm}^{-1}$. The data were acquired using the ATR (attenuated total reflectance) accessory.

A handheld NIR spectrometer (MicroNIR ${ }^{\mathrm{TM}}$ Pro 1700 , Viavi Solutions) was employed for the acquisition of NIR spectral data. The spectra were acquired in the $908-1676 \mathrm{~nm}$ range by averaging 100 scans with an integration time of $12.5 \mathrm{~ms}$ and with absorbance measurements every $6 \mathrm{~nm}$, approximately. The data were acquired in the transmittance mode using a laboratory-made accessory, based on the one described in Paiva et al. ${ }^{11}$ Quartz cuvettes with 2 and $5 \mathrm{~mm}$ optical path lengths were employed in order to evaluate the best option for spectra acquisition.

All spectra acquisitions were performed in triplicate and used as different samples for the calculations.

\section{Data analysis}

Several pre-processing techniques were evaluated, such as standard normal variate (SNV), multiplicative scatter correction (MSC) and $1^{\text {st }}$ and $2^{\text {nd }}$ derivative with a SavitzkyGolay filter $\left(2^{\text {nd }}\right.$ order polynomial with a 15 -point window for MIR data and a 7-point window for NIR data). Before pre-processing, the spectral range from $650-790 \mathrm{~cm}^{-1}$ of the MIR spectra was excluded because it contained high noise. The best pre-processing technique was chosen based on the best results obtained in the partial least squares (PLS) regression models. 
Three types of models were built: $(i)$ models using only the samples of aqueous solutions of ethanol; (ii) models using all samples of aqueous solutions of ethanol plus 2 samples of gel hand sanitizers; and (iii) models with all samples of aqueous solutions of ethanol and 4 samples of gel hand sanitizers. The remaining 7 ethanol-based gel hand sanitizers samples were used to evaluate the prediction ability of the models. Univariate models were also built in order to compare the results. All data analyses were performed using PLS_Toolbox 8 (Eigenvector Research, Inc) in the MATLAB ${ }^{\circledR}$ (MathWorks) environment. ${ }^{12}$

\section{Results and Discussion}

In the MIR region (Figure 1a), the characteristic bands of ethanol and water are related to $\mathrm{O}-\mathrm{H}$ intermolecular hydrogen bond stretching (3400-3200 $\left.\mathrm{cm}^{-1}\right), \mathrm{C}-\mathrm{H}$ stretching (2980 and $\left.2885 \mathrm{~cm}^{-1}\right), \mathrm{H}_{2} \mathrm{O}$ bending $\left(1640 \mathrm{~cm}^{-1}\right)$, $\mathrm{C}-\mathrm{H}$ bending (1380 and $1455 \mathrm{~cm}^{-1}$ ) and $\mathrm{C}-\mathrm{O}$ stretching $\left(1085,1045\right.$ and $\left.880 \mathrm{~cm}^{-1}\right){ }^{13}$

The NIR spectra acquired with the $5 \mathrm{~mm}$ path length cuvette showed saturated absorption signals, particularly in the region between 1400 and $1500 \mathrm{~nm}$. Based on this, the $2 \mathrm{~mm}$ optical path length cuvette was selected for the measurements performed in this work. In the NIR region (Figure 1b), the characteristic bands of ethanol and water are the combination band involving the stretching modes of the water molecule $(1460 \mathrm{~nm})$ and the $\mathrm{O}-\mathrm{H}$ combination band $(1580 \mathrm{~nm}){ }^{14}$

Gel hand sanitizers samples were used in the calibration set to increase variability in the PLS models, as the gel sanitizers have a more complex composition than aqueous

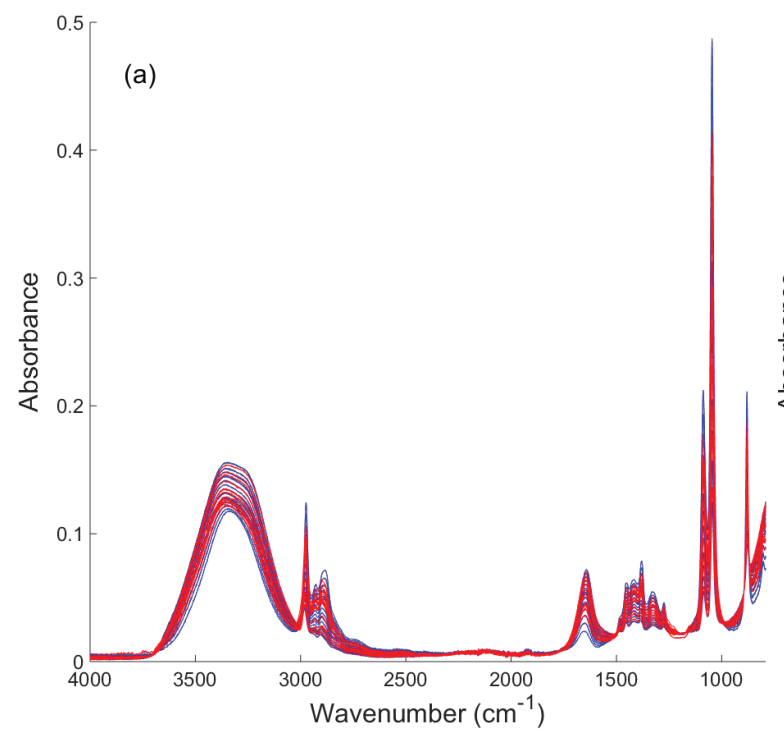

solutions of ethanol. The addition of 2 gel samples (50 and $70 \%$ ethanol content) improved prediction results, with lower values of root mean square error of prediction (RMSEP), mean absolute percentage error (MAPE) and bias when compared to the models without gel samples. However, the addition of 4 gel samples (50, 70, 70 and $80 \%$ ethanol content) did not significantly increase the prediction ability of the model when compared to the models with just 2 gel samples. Therefore, the models with 2 gel samples were selected as the best and they were used to perform the prediction of the remaining 9 gel samples. Univariate models were also built using the variables with the highest variable importance in projection (VIP) scores of the models with 2 gel samples in the calibration set and the best pre-processing techniques. The analytical curves for the univariate models are presented in Supplementary Information (SI) section. The NIR data with MSC preprocessing did not produce a linear univariate model and therefore the $2^{\text {nd }}$ derivative was used. Although the values at only one wavelength were employed to build the univariate models, the spectra (or at least a spectral range) have to be acquired in order to pre-process the data. Only the results with the best pre-processing techniques are presented in Table 1.

The PLS type 2 NIR model presented significantly different values (according to $F$-test at a $95 \%$ confidence level) of root mean square error of cross validation (RMSECV) and RMSEP than the MIR model. Higher values of MAPE of prediction were also observed for the NIR model. These results may be attributed to the use of a handheld spectrometer with a limited spectral range. On the other hand, the handheld spectrometer is a cheaper instrument and can be used on the field.

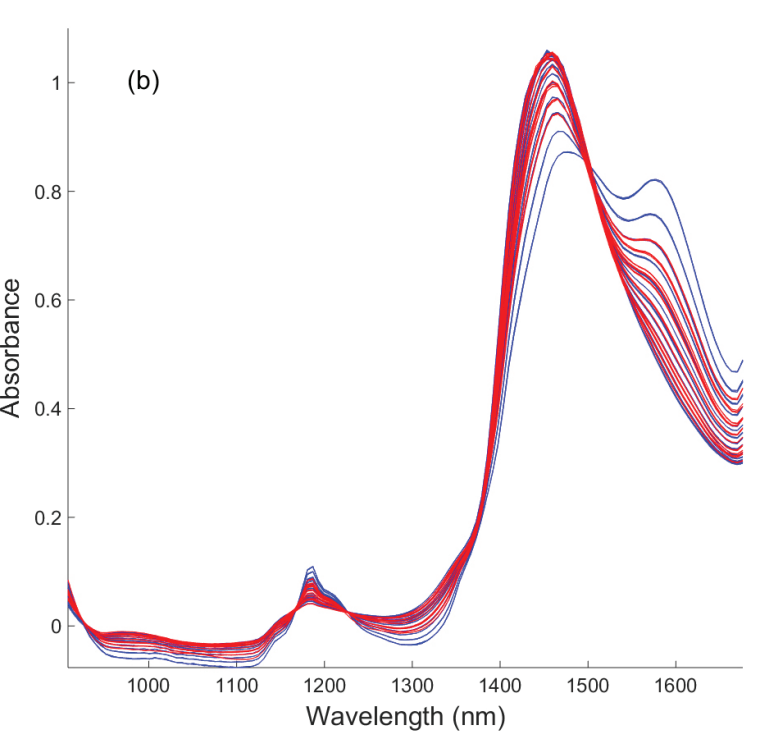

Figure 1. MSC pre-processed spectra in (a) MIR and (b) NIR of aqueous (blue) and gel (red) samples. 
Table 1. Results for the PLS regression and univariate models

\begin{tabular}{|c|c|c|c|c|c|c|c|c|}
\hline & Model & Pre-processing & LVs & $\begin{array}{l}\text { RMSECV / } \\
(\% \mathrm{~m} / \mathrm{m})\end{array}$ & $\begin{array}{l}\text { RMSEP / } \\
(\% \mathrm{~m} / \mathrm{m})\end{array}$ & $\begin{array}{c}\text { Bias of } \\
\text { prediction }\end{array}$ & $\begin{array}{c}\mathrm{R}^{2} \text { of } \\
\text { prediction }\end{array}$ & $\begin{array}{c}\text { MAPE of } \\
\text { prediction } / \%\end{array}$ \\
\hline & type 1 & MSC & 4 & 0.44 & 1.28 & -0.98 & 0.9983 & 1.98 \\
\hline \multirow[t]{3}{*}{ MIR } & type 2 & MSC & 3 & 0.51 & 0.76 & -0.07 & 0.9984 & 1.12 \\
\hline & univariate $\left(1046 \mathrm{~cm}^{-1}\right)$ & MSC & & & 1.61 & 0.90 & 0.9939 & 2.64 \\
\hline & type 1 & $2^{\text {nd }}$ derivative & 4 & 0.77 & 1.38 & 0.50 & 0.9962 & 2.34 \\
\hline \multirow[t]{2}{*}{ NIR } & type 2 & MSC & 4 & 0.68 & 1.18 & -0.28 & 0.9950 & 1.83 \\
\hline & univariate $(1378.87 \mathrm{~nm})$ & $2^{\text {nd }}$ derivative & & & 1.21 & 0.71 & 0.9967 & 2.08 \\
\hline
\end{tabular}

Type 1 model uses only the samples of aqueous solutions of ethanol; type 2 model uses all samples of aqueous solutions of ethanol plus 2 samples of gel hand sanitizers. LVs: latent variables; RMSECV and RMSEP: root mean square error of cross validation and prediction, respectively; $\mathrm{R}^{2}$ : coefficient of determination; MAPE of prediction: mean absolute percentage error of prediction; MIR: mid-infrared; NIR: near-infrared; MSC: multiplicative scatter correction.

Figure 2 shows the predicted versus reference plots for the prediction set (9 gel samples) using PLS (type 2) and univariate models.

Even though the values of RMSEP, MAPE of prediction and bias of the univariate models were higher than the values observed for the multivariate models, the univariate
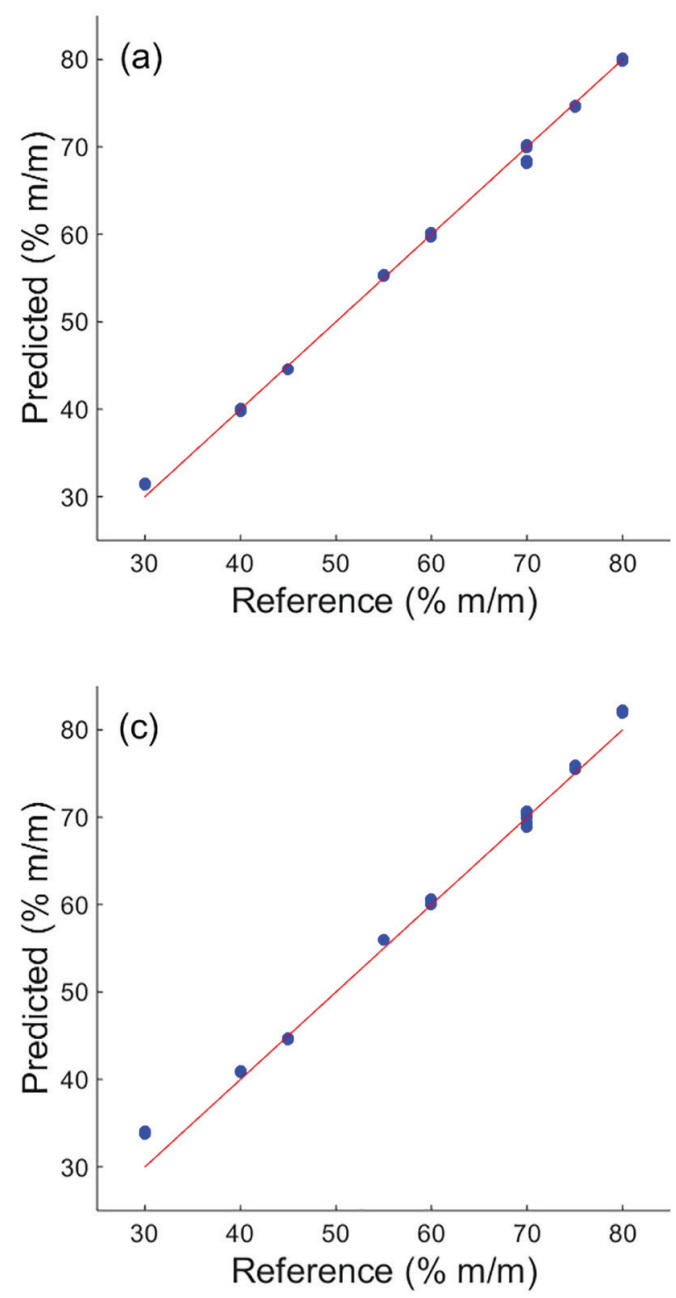

models can still be used if necessary, as long as the variable is obtained from the preprocessed data.

Finally, the commercial and seized samples had their ethanol content determined using the best PLS models. The results (presented in SI section) showed that only 7 samples out of the 34 had an ethanol content of $70 \%(\mathrm{~m} / \mathrm{m})$
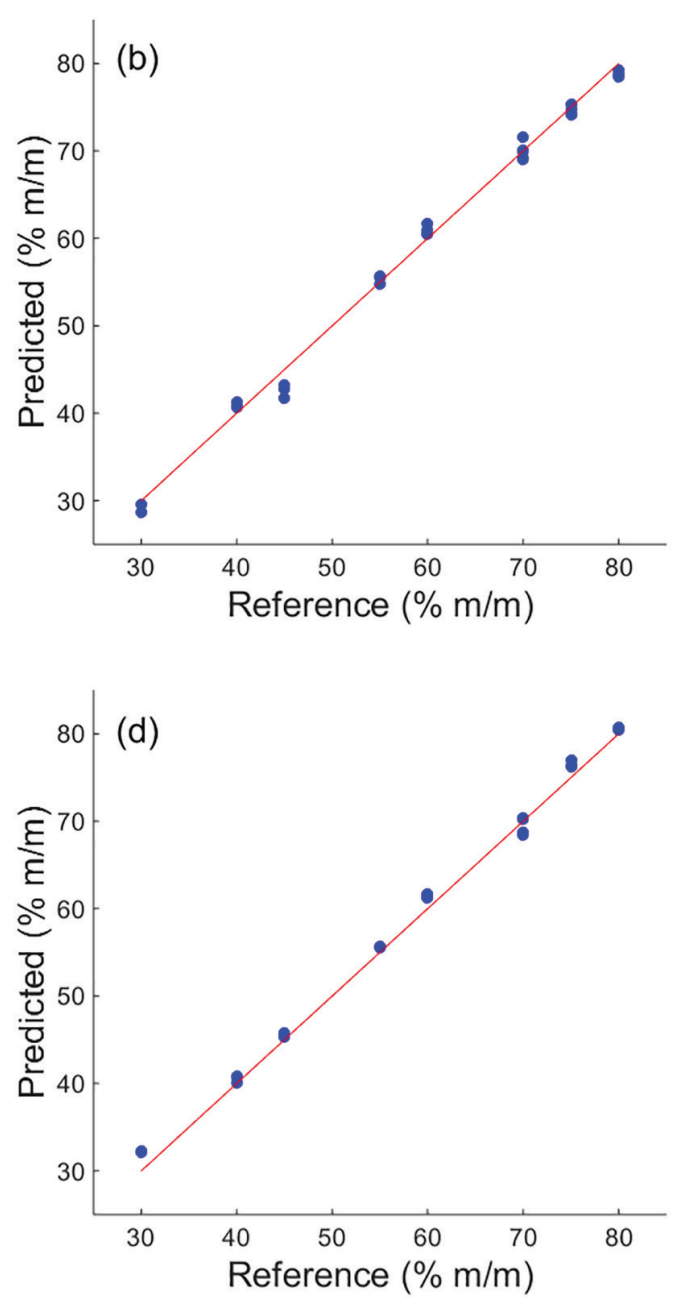

Figure 2. Predicted versus reference plots for the prediction set using type 2 PLS models in the (a) MIR and (b) NIR ranges and univariate models in the (c) MIR and (d) NIR ranges. The line shown is the quadrant bisectrix. 
or higher considering the $95 \%$ confidence interval. The average concentration of these samples' triplicates varied from 23.5 to $75.6 \%(\mathrm{~m} / \mathrm{m})$ and from 20.3 to $77.2 \%(\mathrm{~m} / \mathrm{m})$ using MIR and NIR type 2 models, respectively.

\section{Conclusions}

In this work, simple, fast and non-destructive methods based on MIR and NIR spectra were developed to determine the ethanol content in alcohol-based gel hand sanitizers. These methods are important for the police and regulatory agencies to ensure product quality. They can also be used in industries for quality control purposes. The results demonstrated that the addition of 2 gel samples to the calibration set improved prediction errors and bias compared to models with only aqueous solutions of ethanol and water. Ethanol content in commercial and seized samples was determined using the best PLS models demonstrating that only 7 samples out of the 34 had an ethanol content of $70 \%(\mathrm{~m} / \mathrm{m})$ or higher. This result reinforces the need for constant vigilance by the authorities to ensure that the products have the required specifications.

\section{Supplementary Information}

Supplementary information (Figure S1, Table S1) is available free of charge at http://jbcs.sbq.org.br as PDF file.

\section{Acknowledgments}

The authors would like to acknowledge the Núcleo de Química Analítica Avançada de Pernambuco-NUQAAPE (FACEPE grants APQ-0346-1.06/14), Núcleo de Estudos em Química Forense-NEQUIFOR (CAPES grant AUXPE 3509/2014), CNPq (grant 428891/2018-7), Instituto Nacional de Tecnologias Analíticas Avançadas-INCTAA (CNPq grants 573894/2008-6 and 465768/2014-8) and FAPESP (grants 2008/57808-1 and 2014/50951-4). The authors are grateful to the Pharmaceutical Laboratory of Pernambuco (LAFEPE) for donating samples. The English text of this paper has been revised by Sidney Pratt, Canadian, MAT (The Johns Hopkins University), RSAdipTESL (Cambridge University).

\section{References}

1. Agência Nacional de Vigilância Sanitária (ANVISA); Resolução da Diretoria Colegiada (RDC) No. 350 Define Os Critérios e os Procedimentos Extraordinários e Temporários para a Fabricação e Comercialização de Preparações Antissépticas ou Sanitizantes Oficinais Sem Prévia Autorização da Anvisa e Dá outras Providências, em Virtude da Emergência de Saúde Pública Internacional Relacionada ao SARS-CoV-2; Diário Oficial da União (DOU), Brasília, No. 55, de 20/03/2020, p. 154.

2. U.S. Department of Health and Human Services, Food and Drug Administration (FDA), Center for Drug Evaluation and Research (CDER); Temporary Policy for Manufacture of Alcohol for Incorporation into Alcohol-Based Hand Sanitizer Products During the Public Health Emergency (COVID-19); CDER: Rockville, USA, 2020.

3. Agência Nacional de Vigilância Sanitária (ANVISA); Brazilian Pharmacopoeia National Form, 2n $2^{\text {nd }}$ ed.; ANVISA: Brasília, 2012.

4. Agência Nacional de Vigilância Sanitária (ANVISA); Resolução da Diretoria Colegiada (RDC) No. 42 Dispõe sobre a Obrigatoriedade de Disponibilização de Preparação Alcoólica para Fricção Antisséptica das Mãos, pelos Serviços de Saúde do País, e Dá outras Providências; Diário Oficial da União (DOU), Brasília, de 25/10/2010, p. 27.

5. Mendes, L. S.; Oliveira, F. C. C.; Suarez, P. A. Z.; Rubim, J. C.; Anal. Chim. Acta 2003, 493, 219.

6. Ramasami, P.; Jhaumeer-Laulloo, S.; Cadet, F.; Rondeau, P.; Soophul, Y.; Int. J. Food Sci. Nutr. 2005, 56, 177.

7. Fernandes, H. L.; Raimundo Jr., I. M.; Pasquini, C.; Rohwedder, J. J. R.; Talanta 2008, 75, 804.

8. Nascimento, R. J. A.; Macedo, G. R.; Santos, E. S.; Oliveira, J. A.; Braz. J. Chem. Eng. 2017, 34, 459.

9. Correia, R. M.; Domingos, E.; Cáo, V. M.; Araujo, B. R. F.; Sena, S.; Pinheiro, L. U.; Fonte, A. M.; Aquino, L. F. M.; Ferreira, E. C.; Filgueiras, P. R.; Romão, W.; Talanta 2018, 176, 26.

10. Sales, R.; Silva, N. C.; Silva, J. P.; França, H. H.; Pimentel, M. F.; Stragevitch, L.; Fuel 2019, 254.

11. Paiva, E. M.; Rohwedder, J. J. R.; Pasquini, C.; Pimentel, M. F.; Pereira, C. F.; Fuel 2015, 160, 57.

12. MATLAB, version 7.10.0.499 (R2010a); The MathWorks Inc., USA, 2010.

13. Larkin, P. J.; IR and Raman Spectroscopy: Principles and Spectral Interpretation, $1^{\text {st }}$ ed.; Elsevier: London, UK, 2011.

14. Workman, J.; Weyer, L.; Practical Guide and Spectral Atlas for Interpretive Near-Infrared Spectroscopy, $2^{\text {nd }}$ ed.; CRC Press: Boca Raton, USA, 2012. 